\title{
Preliminary study on stimulatory and inhibitory effects of aldehydes from the green leaf volatiles family on beneficial and pathogenic bacteria from the intestine ${ }^{1)}$
}

\author{
GAMZE GOKER, AHU DEMIRTAS*
}

\begin{abstract}
Department of Surgery, Research and Education Hospital, Suleyman Demirel University, 32260, Isparta, Turkey *Department of Physiology, Faculty of Veterinary Medicine, Burdur Mehmet Akif Ersoy University, 15030, Burdur, Turkey
\end{abstract}

\section{Goker G., Demirtas A. \\ Preliminary study on stimulatory and inhibitory effects of aldehydes from the green leaf volatiles family on beneficial and pathogenic bacteria from the intestine}

Summary

The balance between beneficial and pathogenic bacteria in the intestine has a great importance in terms of gut physiology and immunity. The aim of the study was to investigate the stimulatory and inhibitory effects of aldehydes from the green leaf volatiles family (trans-2-hexenal, cis-3-hexenal, trans-2-nonenal, and trans-2decenal) on beneficial (Bifidobacterium bifidum, Bifidobacterium longum subsp. infantis, Lactobacillus acidophilus, and Lactobacillus casei) and pathogenic bacteria (Fusobacterium nucleatum subsp. nucleatum, Clostridium perfringens, Staphylococcus aureus subsp. aureus, Escherichia coli, and Salmonella enterica subsp. enterica serovar Typhimurium) from the intestine. The growth of $B$. bifidum was stimulated by trans-2-hexenal and trans-2-decenal at 3.9-250 $\mu \mathrm{g} / \mathrm{mL}$, by cis-3-hexenal at 15.6 and $31.3 \mu \mathrm{g} / \mathrm{mL}$, and by trans-2-nonenal at a dose of 3.9-500 $\mu \mathrm{g} / \mathrm{mL}(\mathrm{p}<\mathbf{0 . 0 5})$. Trans-2-decenal also moderately stimulated L. acidophilus at concentrations of 31.3 and $62.5 \mu \mathrm{g} / \mathrm{mL}(\mathrm{p}<0.05)$. Trans-2-hexenal, cis-3-hexenal, and trans-2-nonenal did not inhibit beneficial intestinal bacteria, with the exception of $B$. infantis. Trans-2-decenal was the most effective aldehyde on pathogens, with growth-inhibitory effect on $C$. perfringens, $F$. nucleatum, and $S$. aureus at the concentration of $500 \mu \mathrm{g} / \mathrm{mL}$. Trans-2-decenal also protected beneficial bacteria at the dose at which it inhibited pathogenic ones. All the used aldehydes at a concentration of $500 \mu \mathrm{g} / \mathrm{mL}$ inhibited the growth of $\boldsymbol{F}$. nucleatum as one of the agents of colorectal cancer. Among the pathogens, $E$. coli and $S$. Typhimurium were resistant to all aldehydes while $S$. aureus was inhibited only by trans-2-decenal. In conclusion, the use of aldehydes from the green leaf volatiles family might have beneficial effects on gut health by regulating beneficial bacteria and inhibiting pathogenic bacteria.

Keywords: antibacterial, green leaf volatiles, intestinal bacteria, MIC

Intestinal microflora, which live in a symbiotic relationship with the host, have important metabolic, trophic, and protective functions. Commensal or beneficial bacteria in the gastrointestinal tract of mammals form a natural defensive barrier to the invasion of the intestinal surfaces by exogenous pathogenic microbes. They compete with pathogens for available nutrients and adhesion sites (9). Commensal microflora also promote the modulation and proper maturation of the immune system (25). In particular, lactic acid-

The study was supported by BAP (The Scientific Projects Coordination Unit) of Burdur Mehmet Akif Ersoy University (Project number 0493-YL-18). producing Gram-positive bacteria in the intestine, such as Bifidobacterium spp. and Lactobacillus spp., have beneficial effects in the host; as a matter of fact, many probiotics were originally isolated from the gastrointestinal tract (33).

Disruptions of normal intestinal microbiota in humans and animals is a cause of enteric infections by gut pathogens (35). Ulcerative colitis, irritable bowel syndrome, and colon cancer are other intestinal disorders that are closely related to an unbalanced gastrointestinal microbiota (16). Because conventional antibiotics indiscriminately kill both pathogenic and beneficial 
microbes (3) they have a considerable impact on the microbiota. Furthermore, the extensive use of antibiotics causes the development of bacterial resistance to antibiotics, which leads to the increasing concern about the undesirable effects of antibiotics on public health (8). In recent years, intense interest has arisen in plant extracts and secondary plant metabolites as safer alternatives for antibiotics $(14,29)$. For example, certain essential oils have been reported to show greater toxicity to gut pathogens than to commensals (35). Similarly, extracts of green tea (Camellia sinensis) and Eleutherine americana did not show activity against all commensal microbiota, but inhibited Gram-positive pathogenic bacteria in the intestine (31). On the other hand, plant extracts are composite mixtures of various metabolites, and identification of active compounds responsible for antimicrobial activity poses difficulties for antimicrobial assay studies (6). Therefore, it is recommended to evaluate the antimicrobial activity of single pure plant compounds instead of plant extracts (12).

Green leaf volatiles are composed of C6 compounds, including aldehydes, alcohols, and esters derived from unsaturated fatty acids, linolenic acids, and linoleic acids, via the lipoxygenase pathway (26). The amount of green leaf volatiles is low in healthy plant tissues. They are produced when leaves are injured, infected, or attacked by herbivores and insects (34). Their name originates from the distinctive scent that is emitted when leaves are crushed. Hexenal, trans-2-hexenal, trans-3-hexenal, and cis-3-hexenal are the most common $\mathrm{C} 6$ aldehydes from the green leaf volatiles family (26). Trans-2-nonenal (C9) and trans-2-decenal (C10) are longer-chain aldehydes that are produced from hemiacetals by plants and have similar properties to all other C6 aldehydes $(17,24)$. The aldehydes from the green leaf volatiles family, such as nonanal, decanal, dodecanal, octanal, and undecanal, have been granted a "generally recognized as safe" status (15). Trans-2-hexenal also tested negatively for mutagenicity (1).

Green leaf volatiles show a broad-spectrum antimicrobial activity against several fungal and bacterial microorganisms $(20,27)$. However, bacteriostatic activity of aldehyde compounds was greater than that of the alcohol ones (27). In a previous study, we observed that cis-3-hexenal increased the abundance of some Grampositive anaerobic fermenters, such as Butyrivibrio fibrisolvens and Streptecoccus bovis, in a simulated rumen (13). Although there are a few reports about the effects of some green-leaf-derived compounds on some agents of gastrointestinal tract infections $(4,21$, 27 ), the effects of green leaf volatiles on beneficial gut bacteria have not been evaluated previously.

Therefore, the aim of the present study was to investigate the stimulatory and inhibitory effects of aldehydes from the green leaf volatiles family on both beneficial and pathogenic bacteria from the intestine.

\section{Material and methods}

Commercial aldehydes. Commercial aldehydes from green leaf volatiles family, cis-3-hexenal (W256102), trans2-nonenal (W321303), and trans-2-decenal (W236608) were obtained from Sigma-Aldrich. Trans-2-hexenal (A11513) was purchased from Alfa Aesar.

Intestinal bacterial strains and culture conditions. Beneficial bacterial species used in antimicrobial tests were Bifidobacterium bifidum ATCC 29521, Bifidobacterium longum subsp. infantis ATCC 15697, Lactobacillus acidophilus ATCC 4356, and Lactobacillus casei ATCC 393. Pathogenic bacterial species tested were Fusobacterium nucleatum subsp. nucleatum ATCC 25586, Clostridium perfringens ATCC 13124, Staphylococcus aureus subsp. aureus ATCC 12600, Escherichia coli ATCC 11775, and Salmonella enterica subsp. enterica serovar Typhimurium ATCC 29630.

The media used to culture different intestinal strains were as follows: B. bifidum, Mann Rogosa Sharpe (MRS) broth with $0.05 \%$ cysteine (MRS-C); L. acidophilus, MRS broth; $E$. coli and $S$. Typhimurium, Luria-Bertani (LB) medium; S. aureus, tryptic soy broth (TSB); and B. infantis, L. casei, $C$. perfringens, and $F$. nucleatum, liquid form of medium 2 (18). Medium 2 was prepared under $\mathrm{CO}_{2}$, as previously described (18) with only slight modification. Trypticase peptone was used instead of casitone in medium 2 (Tab. 1). E. coli, $S$. Typhimurium, and $S$. aureus were grown aerobically at $37^{\circ} \mathrm{C}$ for $24 \mathrm{~h}$. All others were grown at $37^{\circ} \mathrm{C}$ for 24-72 $\mathrm{h}$ under an atmosphere of $80 \% \mathrm{~N}_{2}, 10 \% \mathrm{CO}_{2}$, and $10 \% \mathrm{H}_{2}$ in an anaerobic chamber (Whitley DG250, Don Whitley, West Yorkshire, UK).

Tab. 1. Composition of medium 2 (for $100 \mathrm{~mL}$ )

\begin{tabular}{|c|c|}
\hline Component & \\
\hline Trypticase peptone (BD 211921 Bacto $^{T M}$ ) & $1.0 \mathrm{~g}$ \\
\hline Yeast extract (Sigma Y1625) & $0.25 \mathrm{~g}$ \\
\hline Mineral solution 1 & $15 \mathrm{~mL}$ \\
\hline Mineral solution 2 & $15 \mathrm{~mL}$ \\
\hline Clarified rumen fluid & $20 \mathrm{~mL}$ \\
\hline Resazurin (Sigma R7017) & $0.0001 \mathrm{~g}$ \\
\hline Sodium lactate $(70 \% \mathrm{w} / \mathrm{v})$ & $1.0 \mathrm{~g}$ \\
\hline Glucose & $0.2 \mathrm{~g}$ \\
\hline Maltose & $0.2 \mathrm{~g}$ \\
\hline Cellobiose (Sigma 22150) & $0.2 \mathrm{~g}$ \\
\hline Cysteine HCI (Sigma C7880) & $0.05 \mathrm{~g}$ \\
\hline $\mathrm{NaHCO}_{3}$ (Sigma S5761) & $0.4 \mathrm{~g}$ \\
\hline Deionized water & to $100 \mathrm{~mL}$ \\
\hline
\end{tabular}

Explanations: mineral solution $1-3 \mathrm{~g} / \mathrm{L} \mathrm{K}_{2} \mathrm{HPO}_{4}$ (Sigma P3786); mineral solution $2-3 \mathrm{~g} / \mathrm{L} \mathrm{KH}_{2} \mathrm{PO}_{4}$ (Sigma P9791), $6 \mathrm{~g} / \mathrm{L}$ $\left(\mathrm{NH}_{4}\right)_{2} \mathrm{SO}_{4}$ (Sigma A4915), $6 \mathrm{~g} / \mathrm{L} \mathrm{NaCl}$ (Sigma S7653), $0.6 \mathrm{~g} / \mathrm{L}$ $\mathrm{MgSO}_{4} \cdot 7 \mathrm{H}_{2} \mathrm{O}$ (Sigma 230391), and $0.6 \mathrm{~g} / \mathrm{L} \mathrm{CaCl}_{2}$ (Sigma C1016); clarified rumen fluid - ruminal fluid brought from the slaughterhouse was mixed and filtered through three layers of cheesecloth to partition into liquid and solid (digesta) fractions. The liquid fraction was centrifuged at $15000 \mathrm{rpm}$, and the clear supernatant was used as a component of the anaerobic media. 
Determination of minimal inhibitor concentrations (MIC). The broth dilution method was conducted in the anaerobic chamber. Tests for $E$. coli, $S$. Typhimurium, and $S$. aureus were carried out in a laminar flow cabinet. Aldehydes were dissolved in 50\% ethanol. MICs of green leaf aldehydes were evaluated at doses ranging from 0.015 to $1000 \mu \mathrm{g} / \mathrm{mL}$ in the literature $(4,21,27)$. In the present study, green leaf volatiles were tested at $1000,500,250,125,62.5,31.3,15.6,7.8$, and $3.9 \mu \mathrm{g} / \mathrm{mL}$ concentrations. Dilutions of aldehydes were made in the bacterial strain specific growth media. Two hundred microliters of each dilution were distributed over a 96-well plate (Corning 3599 , Flat bottom). Next, $20 \mu \mathrm{L}$ of overnight bacterial cultures at a density of $4 \times 10^{10}$ cell $/ \mathrm{mL}$ were inoculated into each well $(10,13)$. Three wells were used for each concentration. At the same time, negative control wells without aldehydes and media control wells without bacteria were maintained for each set. Plates were incubated at $37^{\circ} \mathrm{C}$ for $24 \mathrm{~h}$ in the anaerobic chamber and in an incubator for $E$. coli, $S$. Typhimurium, and $S$. aureus. Bacterial growth was determined at $600 \mathrm{~nm}$ using a microplate reader (Epoch, BioTek,
USA). The MIC was recorded as the lowest aldehyde concentration at an OD600 value of $\leq 0.1$.

Statistical analyses. Statistical analysis was carried out by the use of one-way ANOVA followed by Dunnett's test. Each well of a 96-well plate was an experimental unit. A value of $p<0.05$ was taken to indicate a significant difference.

Tab. 2. Minimum inhibitory concentration (MIC) values of aldehydes from the green leaf volatiles family on beneficial and pathogenic bacteria from the intestine

\begin{tabular}{|c|c|c|c|c|}
\hline \multirow{2}{*}{ Bacteria } & \multicolumn{4}{|c|}{ MIC values ( $\mu \mathrm{g} / \mathrm{mL})$} \\
\hline & trans-2-hexenal & cis-3-hexenal & trans-2-nonenal & trans-2-decenal \\
\hline \multicolumn{5}{|l|}{ Beneficials } \\
\hline B. bifidum & - & - & - & 1000 \\
\hline B. infantis & 1000 & 1000 & 1000 & 1000 \\
\hline L. acidophilus & - & - & - & 1000 \\
\hline L. casei & - & - & - & 1000 \\
\hline \multicolumn{5}{|l|}{ Pathogens } \\
\hline F. nucleatum & 500 & 500 & 500 & 500 \\
\hline C. perfringens & - & 1000 & 1000 & 500 \\
\hline S. aureus & - & - & - & 500 \\
\hline E. coli & - & - & - & - \\
\hline S. Typhimurium & - & - & - & - \\
\hline
\end{tabular}

Explanations: (-) MIC values are higher than $1000 \mu \mathrm{g} / \mathrm{mL}$

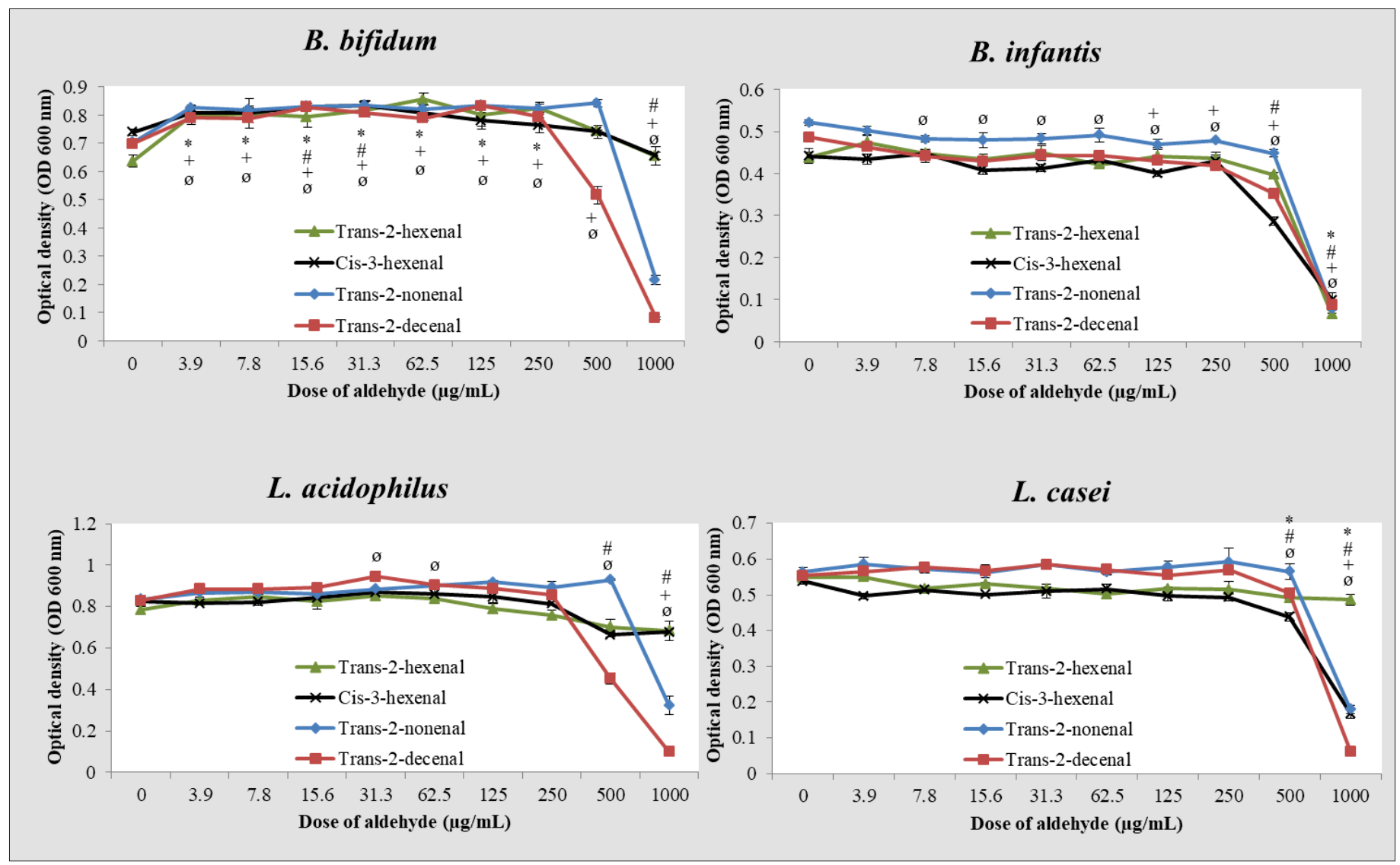

Fig. 1. Effects of aldehydes from the green leaf volatiles family on beneficial intestinal bacteria. The results represent the mean \pm standard error. ${ }^{*} \mathbf{p}<\mathbf{0 . 0 5}$, difference of the trans-2-hexenal-treated culture compared with the control; ${ }^{\#} \mathbf{p}<0.05$, difference of the cis-3-hexenal-treated culture compared with the control; ${ }^{+} p<0.05$, difference of the trans-2-nonenal-treated culture compared with the control; and ${ }^{\circ} \mathrm{p}<\mathbf{0 . 0 5}$, difference of the trans-2-decenal-treated culture compared with the control. Control level was $0 \mu \mathrm{g} / \mathrm{mL}$ for each aldehyde. 


\section{Results and discussion}

Effects of aldehydes from the green leaf volatiles family on intestinal bacteria are presented in Figure 1 and Figure 2, and the MIC values are summarized in Table 2 . The growth of $B$. bifidum was stimulated by trans-2-hexenal and trans-2-decenal at 3.9-250 $\mu \mathrm{g} / \mathrm{mL}$, by cis-3-hexenal at 15.6 and $31.3 \mu \mathrm{g} / \mathrm{mL}$, and by trans2 -nonenal at $3.9-500 \mu \mathrm{g} / \mathrm{mL}$ dosage $(\mathrm{p}<0.05)$. Trans2-decenal also moderately stimulated $L$. acidophilus at concentrations of 31.3 and $62.5 \mu \mathrm{g} / \mathrm{mL}(\mathrm{p}<0.05)$. Green leaf volatiles failed to promote the growth of other beneficial gut bacteria. Nonetheless, trans-2-hexenal, cis-3-hexenal, and trans-2-nonenal did not show growth-inhibitory activity toward beneficial bacteria, except $B$. infantis, which was inhibited by the use of $1000 \mu \mathrm{g} / \mathrm{mL}$ concentrations of these aldehydes. Trans2-decenal, on the other hand, exhibited antibacterial activity on beneficial bacteria when used at $1000 \mu \mathrm{g} /$ $\mathrm{mL}$. Trans-2-decenal was also the most effective aldehyde on pathogens, with a growth-inhibitory effect on $C$. perfringens, $F$. nucleatum, and $S$. aureus at the concentration of $500 \mu \mathrm{g} / \mathrm{mL}$. Both cis-3-hexenal and trans-2-nonenal inhibited $C$. perfringens and $F$. nucleatum at doses of 1000 and $500 \mu \mathrm{g} / \mathrm{mL}$, respectively. Trans-2-hexenal was less toxic to all pathogenic bacteria; it inhibited only F. nucleatum at $500 \mu \mathrm{g} / \mathrm{mL}$. E.coli and $S$. Typhimurium from pathogens were resistant to all aldehydes while $S$. aureus was inhibited only by trans-2-decenal.
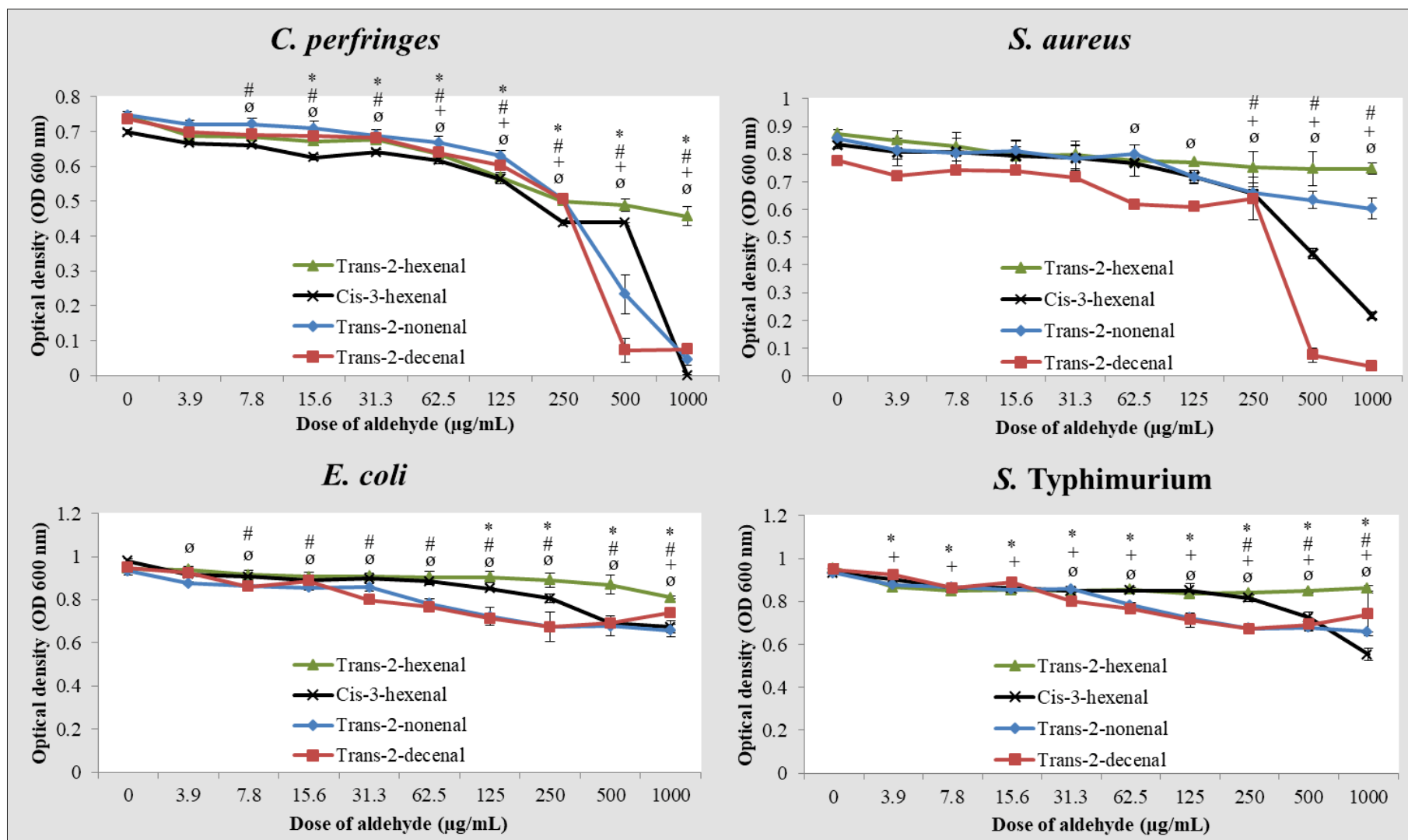

\section{F. nucleatum}

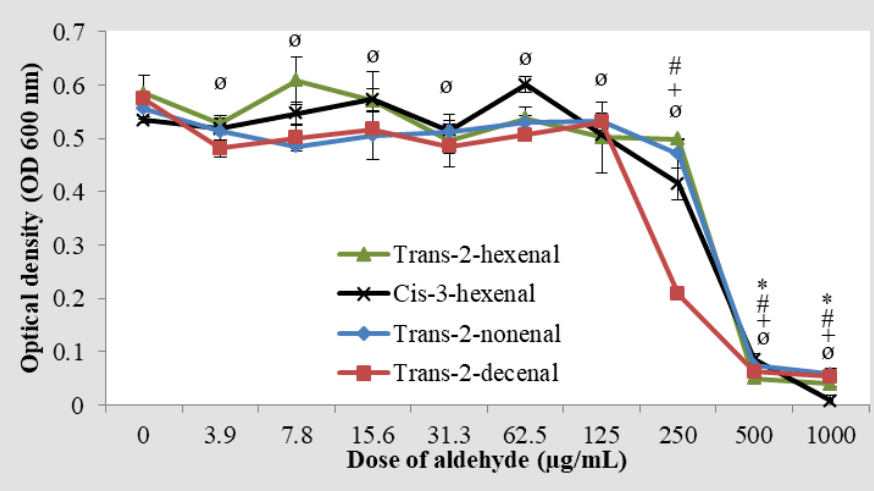

Fig. 2. Effects of aldehydes from the green leaf volatiles family on pathogenic intestinal bacteria. The results represent the mean \pm standard error. " $p<0.05$, difference of the trans-2-hexenal-treated culture compared with the control; ${ }^{\#} p<0.05$, difference of the cis-3-hexenal-treated culture compared with the control; ${ }^{+} p<0.05$, difference of the trans-2-nonenal-treated culture compared with the control; and ${ }^{\circ} \mathrm{p}<0.05$, difference of the trans-2-decenal-treated culture compared with the control. Control level was $0 \mu \mathrm{g} / \mathrm{mL}$ for each aldehyde. 
Beneficial microbes in the gut have collective physiological functions almost equal to an organ within the host (28). The major physiologic function of these symbiotic microbes is the fermentation of nondigestible carbohydrates and generation of short-chain fatty acids, mainly acetate, propionate, and butyrate, which are the primary energy sources of the intestinal epithelium (9). Differently from the others, butyrate inhibits the proliferation and stimulates the differentiation of epithelial cells; it can therefore suppress the viability and growth of colorectal cancer cell lines (7). According to a review of 31 original articles on the role of colon microbiota in colorectal cancer observed in humans and animals, beneficial bacteria such as Bifidobacterium, Lactobacillus, Ruminococcus, and Faecalibacterium spp. were consistently diminished while some bacteria, including Fusobacteria and Staphylococcaceae, were consistently augmented (5). In particular, Fusobacterium nucleatum is linked with colorectal cancer because it induces DNA damage, stimulates inflammation, and can shield tumors from immune attack (7). In the present study, all aldehydes from the green leaf volatiles family inhibited the growth of $F$. nucleatum at a concentration of $500 \mu \mathrm{g} / \mathrm{mL}$ while they protected the beneficial microbes at the same dose. There is no literature on the effects of green leaf volatiles on this bacterium. However, extracts of a series of medical plants did not inhibit $F$. nucleatum isolated from periodontal pockets of periodontic patients up to $16384 \mathrm{mg} / \mathrm{L}$, while the MIC value of spiramycin, a commercially used antibiotic, on F. nucleatum was $64 \mathrm{mg} / \mathrm{L}$ in the same study (19).

$C$. perfringens and $S$. aureus are Gram-positive food-borne pathogens that can cause enterotoxaemia and severe gastro-intestinal illness (32). Trans-2decenal, at a concentration of $500 \mu \mathrm{g} / \mathrm{mL}$, showed antimicrobial activity on both of these bacteria in this study. Bisignano et al. (4) also reported that trans2-decenal was effective on $S$. aureus (ATCC 6538) at a concentration of $250 \mu \mathrm{g} / \mathrm{mL}$ and methicillin-resistant $S$. aureus at concentrations of $125-500 \mu \mathrm{g} / \mathrm{mL}$, which were similar to our findings. Trans-2-decenal was the unique aldehyde that had an antimicrobial effect on $S$. aureus in the present study. Additionally, the MIC value of trans-2-decenal was lower than trans-2-nonenal and cis-3-hexenal on $C$. perfringens. Kubo et al. (21) linked the degree of antimicrobial activity of $\alpha / \beta$ unsaturated alcohols and aldehydes with the hydrophobic alkyl (tail) chain length and the microorganism being tested. The researchers suggested that aldehydes with a long chain length exhibit more potent activity against Gram-positive bacteria and fungi. They submitted that electronegativity of the oxygen atom in the aldehydes may be influenced by differences in carbon tail length. Greater chain length could cause greater electronegativity, which can cause greater affinity for hydrogen bond formation with nucleophilic groups of the membrane, creating significant disruption in

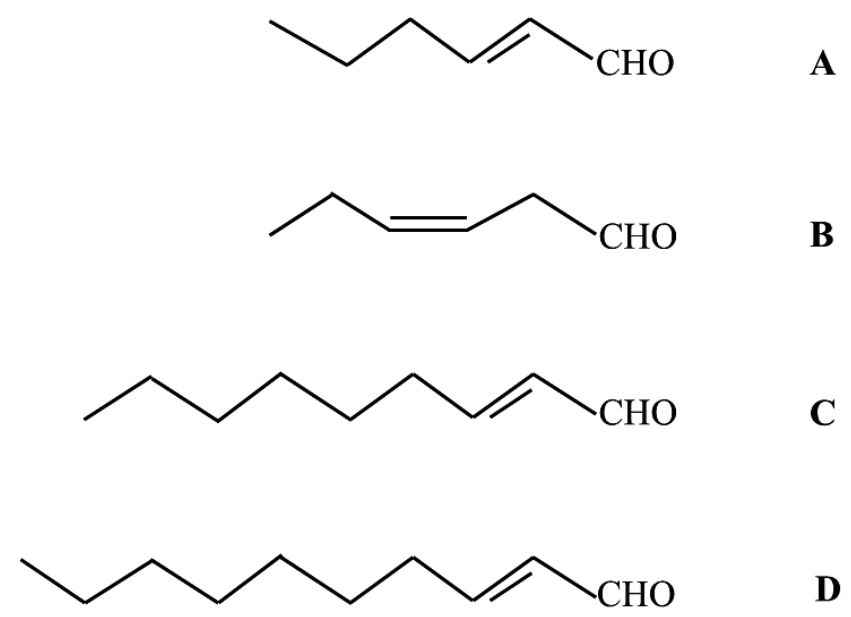

Fig. 3. Chemical structure of (A) trans-2-hexenal, (B) cis-3-hexenal, (C) trans-2-nonenal, and (D) trans-2-decenal

the lipid bilayer of the microorganism (21). The chain length of trans-2-decenal was composed of C10 as shown in Figure 3. In the previous study of the same researchers (22), geranyl acetol with the same chain length (C10) also exhibited activity against $S$. aureus while linalool, of which the chain length composed of C6, did not show any activity.

The aldehydes from green leaf volatiles used in this study did not show antimicrobial activity against $E$. coli or $S$. Typhimurium. Trans-2-decenal was ineffective on E. coli up to $800 \mu \mathrm{g} / \mathrm{mL}(21)$, which was similar to the present study. Cho et al. (11) also reported that a higher concentration of trans-2-nonenal, at $1.000 \mathrm{ppm}$, was required to kill E. coli O157:H7 and Salmonella Typhimurium. On the other hand, trans-2-hexenal and cis-3-hexenal, at doses of $6.25-100 \mu \mathrm{g} / \mathrm{mL}$, inhibit $E$. coli $\mathrm{O}-157: \mathrm{H} 7$, according to a report of Nakamura and Hatanaka (27), which is contrary to our results. The strain of $E$. coli in the present study was $\mathrm{O} 1: \mathrm{K} 1: \mathrm{H} 7$. The reason for these variable results might be related to the different types of strains of bacteria.

Green leaf volatile aldehydes moderately promote the growth of some beneficial gut bacteria like $B$. bifidum and L. acidophilus at lower concentrations. In a previous study, low concentrations of trans-2-hexenal and trans-2-decenal also stimulated the growth of pure cultures of Fibrobacter succinogenes, which contribute to pre-gastric cellulose fermentation in ruminants (13). Saponins, one of the phytochemicals, promoted in vitro bacterial growth and feed utilization in the rumen at low doses while they exhibited inhibition at high doses (30). The researchers indicated that gut bacteria can hydrolyze some plant metabolites, such as flavonoids and phenolic acids, to protect themselves against the toxic effects of these compounds $(2,23)$. Bacterial degradation products are usually more bioactive than precursors, hence, they can stimulate the enzymatic activity of certain groups of bacteria in the gut $(2,23)$.

In conclusion, in the present study, green leaf volatile aldehydes moderately promoted the growth of some beneficial gut bacteria at lower concentrations. Trans- 
2-hexenal, cis-3-hexenal, and trans-2-nonenal did not inhibit beneficial intestinal bacteria, with the exception of $B$. infantis; nevertheless, their antimicrobial activity on pathogens was weaker than that of trans-2-decenal. Trans-2-decenal also protected beneficial bacteria at the dose at which it inhibited pathogenic ones. All the used aldehydes have a potential to diminish F. nucleatum as one of the agents of colorectal cancer. Further studies are required on the effects of green leaf volatile aldehydes in mixed cultures of intestinal microbiota and in vivo to evaluate the interplay between different bacterial species and to determine the value of green leaf volatiles as food supplements and enteric infection inhibitors.

\section{References}

1.Andersen R. A., Hamilton-Kemp T. R., Hildebrand D. F., McCracken C. T. Collins $R$. W., Fleming P. D.: Structure antifungal activity relationships among volatile C6 and C9 aliphatic aldehydes, ketones, and alcohols. J. Agric. Food Chem. 1994, 42, 1563-1568.

2. Aura A. M.: Microbial metabolism of dietary phenolic compounds in the colon. Phytochem. Rev. 2008, 7, 407-429.

3. Bäumler A. J., Sperandio $V$.: Interactions between the microbiota and pathogenic bacteria in the gut. Nature 2016, 535, 85-93.

4. Bisignano G., Lagana M. G., Trombetta D., Arena S., Nostro A., Uccella N., Mazzanti $G$., Saija A.: In vitro antibacterial activity of some aliphatic aldehydes from Olea europaea L. FEMS Microbiol. Lett. 2001, 198, 9-13

5. Borges-Canha M., Portela-Cidade J. P., Dinis Ribeiro M., Leite-Moreira A. F., Pimentel-Nunes P.: Role of colonic microbiota in colorectal carcinogenesis a systematic review. Rev. Esp. Enferm. Dig. 2015, 107, 659-671.

6. Broudiscou L. P., Papon Y., Broudiscou A. F.: Effects of dry plant extracts on feed degradation and the production of rumen microbial biomass in a dual outflow fermenter. Anim. Feed Sci. Tech. 2002, 101, 183-189.

7. Bultman $S$. J.: The microbiome and its potential as a cancer preventive intervention. Semin. Oncol. 2016, 43, 97-106.

8. Caniça M., Manageiro V., Abriouel H., Moran-Gilad J., Franz C. M.: Antibiotic resistance in foodborne bacteria. Trends Food Sci. Tech. 2019, 84, 41-44.

9. Canny G. O., McCormick B. A.: Bacteria in the intestine, helpful residents or enemies from within? Infect. Immun. 2008, 76, 3360-3373.

10. Chauhan A. K., Kang S. C.: Thymol disrupts the membrane integrity of Salmonella ser. typhimurium in vitro and recovers infected macrophages from oxidative stress in an ex vivo model. Res. Microbiol. 2014, 165, 559-565.

11. Cho M. J., Buescher R. W., Johnson M., Janes M.: Inactivation of pathogenic bacteria by cucumber volatiles (E, Z)-2, 6-nonadienal and (E)-2-nonenal. J. Food Protect. 2004, 67, 1014-1016.

12. Cobellis G., Trabalza-Marinucci M., Yu Z.: Critical evaluation of essential oils as rumen modifiers in ruminant nutrition: a review. Sci. Total Environ. 2016, 545, 556-568.

13. Demirtas A., Ozturk H., Sudagidan M., Keyvan E., Yavuz O., Gulay O. Y., Musa S. A. A.: Effects of commercial aldehydes from green leaf volatiles (green odour) on rumen microbial population and fermentation profile in an artificial rumen (Rusitec). Anaerobe 2019, 55, 83-92.

14. Di Giulio M., Genovese S., Fiorito S., Epifano F., Nostro A., Cellini L.: Antimicrobial evaluation of selected naturally occurring oxyprenylated secondary metabolites. Nat. Prod. Res. 2016, 30, 1870-1874.

15. Feron V. J., Til H. P., De Vrijer F., Woutersen R. A., Cassee F. R., Van Bladeren P. J.: Aldehydes: occurrence, carcinogenic potential, mechanism of action and risk assessment. Mutat. Res. 1991, 259, 363-385.

16. Flint H. J., Wallace R. J.: Obesity and colorectal cancer risk: impact of the gut microbiota and weight-loss diets. Open Obes. J. 2010, 2, 50-62.

17. Hirao T., Okazawa A., Harada K., Kobayashi A., Muranaka T., Hirata K.: Green leaf volatiles enhance methyl jasmonate response in Arabidopsis. J. Biosci. Bioeng. 2012, 114, 540-545.

18. Hobson P. N.: Rumen bacteria, [in:] Methods in microbiology. Academic Press, London and New York 1969, p. 133-149.

19. Iauk L., Lo Bue A. M., Milazzo I., Rapisarda A., Blandino G.: Antibacterial activity of medicinal plant extracts against periodontopathic bacteria. Phytother Res. 2003, 17, 599-604.

20. Kishimoto K., Matsui K., Ozawa R., Takabayashi J.: Direct fungicidal activities of C6-aldehydes are important constituents for defence responses in Arabidopsis against Botrytis cinerea. Phytochemistry 2008, 69, 2127-2132.
21. Kubo A., Lunde C. S., Kubo I.: Antimicrobial activity of the olive oil flavor compounds. J. Agr. Food Chem. 1995, 43, 1629-1633.

22. Kubo I., Muroi H., Masaki H., Kubo A.: Antibacterial activity of long-chain alcohols: the role of hydrophobic alkyl groups. Bioorg. Med. Chem. Lett. 1993, 3, 1305-1308

23. Lampe J. W. Chang J. L.: Interindividual differences in phyto-chemical metabolism and disposition. Semin. Cancer Biol. 2007, 17, 347-353.

24. Lee M. R. F., Huws S. A., Scollan N. D., Dewhurst R. J.: Effects of fatty acid oxidation products (green odor) on rumen bacterial populations and lipid metabolism in vitro. J. Dairy Sci. 2007, 90, 3874-3882.

25. Marchesi J. R., Adams D. H., Fava F., Hermes G. D., Hirschfield G. M. Hold G., Quraishi M. N., Kinross J., Smidt H., Tuohy K. M., Thomas L. V., Zoetendal E. G., Hart A.: The gut microbiota and host health: a new clinical frontier. Gut 2016, 65, 330-339.

26. Matsui $K$ : Green leaf volatiles: hydroperoxide lyase pathway of oxylipin metabolism. Curr. Opin. Plant Biol. 2006, 9, 274-280.

27. Nakamura S., Hatanaka A.: Green-leaf-derived C6-aroma compounds with potent antibacterial action that act on both Gram-negative and Gram-positive bacteria. J. Agr. Food Chem. 2002, 50, 7639-7644.

28. O'Hara A. M., Shanahan F.: The gut flora as a forgotten organ. EMBO Rep. 2006, 7, 688-693.

29. Palaniappan K., Holley R. A.: Use of natural antimicrobials to increase antibiotic susceptibility of drug resistant bacteria. Int. J. Food Microbiol. 2010, 140, 164-168.

30. Patra A. K., Stiverson J., Yu Z.: Effects of quillaja and yucca saponins on communities and select populations of rumen bacteria and archaea, and fermentation in vitro. J. Appl. Microbiol. 2012, 113, 1329-1340.

31. Phoem A. N., Voravuthikunchai S. P.: Growth stimulation/inhibition effect of medicinal plants on human intestinal microbiota. Food Sci. Biotechnol. 2012, 21, 739-745

32. Rajkovic A.: Microbial toxins and low level of foodborne exposure. Trends Food Sci. Tech. 2014, 38, 149-157.

33. Sánchez B., Delgado S., Blanco-Míguez A., Lourenço A., Gueimonde M., Margolles A.: Probiotics, gut microbiota, and their influence on host health and disease. Mol. Nutr. Food Res. 2017, 61, 1600240.

34. Scala A., Allmann S., Mirabella R., Haring M., Schuurink R.: Green leaf volatiles: a plant's multifunctional weapon against herbivores and pathogens. Int. J. Mol. Sci. 2013, 14, 17781-17811.

35. Thapa D., Losa R., Zweifel B., Wallace R. J.: Sensitivity of pathogenic and commensal bacteria from the human colon to essential oils. Microbiology $2012,158,2870-2877$.

Corresponding author: Ahu Demirtas, Asst. Prof.; e-mail: ahudemirtas@ mehmetakif.edu.tr 